\title{
Estimasi temperatur bawah permukaan reservoir Gunung Lumpur Bledug Kuwu (GLBK) Jawa Tengah menggunakan metode geotermometri
}

\author{
1,2* Aryono Adhi, ${ }^{3} \mathrm{~W}$ Wahyudi, ${ }^{3}$ Wiwit Suryanto, ${ }^{3} \mathrm{~S}$ Sismanto, ${ }^{2}$ Agus Suprianto, ${ }^{1} \mathrm{E}$ \\ Ellianawati \\ 1Jurusan Fisika, Universitas Negeri Semarang, Kampus Sekaran Gunungpati Semarang 50229, Indonesia \\ 2Program Doktor Departemen Fisika, Universitas Gadjah Mada Yogyakarta, Sekip Utara Bulaksumur \\ Yogyakarta 55281, Indonesia \\ ${ }^{3}$ Departemen Fisika, Universitas Gadjah Mada Yogyakarta, Sekip Utara Bulaksumur Yogyakarta 55281 \\ Indonesia \\ e-mail: aryono_adhi@yahoo.com
}

\begin{abstract}
Abstrak
Studi literatur untuk mengestimasi temperatur reservoir Gunung Lumpur Bledug Kuwu telah dilakukan menggunakan metode geotermometri larutan. Perhitungan temperatur diperoleh dari hasil perhitungan empiris kandungan unsur-unsur kimia terlarut pada air panas Gunung Lumpur Bledug Kuwu. Kandungan unsur ini diperoleh dari hasil analisis sampel air panas dengan metode Atomic Absorption Spectrophotometer (AAS) yang dilakukan oleh Rizqiya 2014, berupa konsentrasi $\mathrm{Na}, \mathrm{K}, \mathrm{Ca}, \mathrm{Mg}$ dan $\mathrm{SiO}_{2}$. Dari hasil perhitungan ini, estimasi temperatur bawah permukaan reservoir sumber panas di Bledug Kuwu berkisar antara $90.411-148.354{ }^{\circ} \mathrm{C}$.
\end{abstract}

Kata Kunci: temperatur; reservoir; geotermometri; Bledug Kuwu

\section{Estimation of subsurface temperature of the reservoir of Gunung Mud Bledug Kuwu (GLBK) in Central Java using the geothermal method}

\begin{abstract}
The literature study to estimate the reservoir temperatur of the Bledug Kuwu Mud Mountain has been carried out using a geothermometry method. Calculation of temperature is obtained from the empirical calculation of the content of dissolved chemical elements in the Bledug Kuwu Mud Volcano hot spring. The content of this element is obtained from the results of analysis of hot water samples using the Atomic Absorption Spectrophotometer (AAS) method conducted by Rizqiya 2014, in the form of concentrations of $\mathrm{Na}, \mathrm{K}, \mathrm{Ca}, \mathrm{Mg}$ and $\mathrm{SiO}_{2}$. From the results of this calculation, the sub-surface temperature estimation of the Bledug Kuwu reservoir ranges from $90,411-148,354{ }^{\circ} \mathrm{C}$
\end{abstract}

Keywords: temperature; reservoir; geotermometri; Bledug Kuwu

How to Cite: Adhi, A., Wahyudi, W., Suryanto, W., Sismanto, S., Suprianto, A., \& Ellianawati, E. (2019). Estimasi temperatur bawah permukaan reservoir Gunung Lumpur Bledug Kuwu (GLBK) Jawa Tengah menggunakan metode Geotermometri. Jurnal Pendidikan Fisika dan Keilmuan (JPFK), 5(1), 1-6. doi:http://dx.doi.org/10.25273/jpfk.v5i1.3425

\section{PENDAHULUAN}

Bledug Kuwu yang terletak di Desa Kuwu, Kecamatan Kradenan, Kabupaten Grobogan, Provinsi Jawa Tengah merupakan salah satu Gunung Lumpur (mud Volcano) yang ada di wilayah ini dan terjadi karena proses alam (Istadi, Wibowo, Sunardi, Hadi, \& Sawolo, 2012). Gunung Lumpur Bledug Kuwu (GLBK) mempunyai karakteristik unik yaitu terjadi letupan-letupan gas CO2 yang keluar dari lubang kawah lumpur secara berkala dalam durasi 3-4 menit (Queißer et al., 2017)ok dan temperatur yang lebih tinggi dari lingkungan (Siregar \& Siregar, 2016). Sumber 
gas $\mathrm{CO} 2$ secara alamiah yang terjadi di alam bisa disebabkan oleh proses biogenic akibat reaksi anaerob (Syaichurrozi, 2017) dan geologi seperti reaksi metamorfosis karbonat dan magmatic degassing pada proses panasbumi (Queißer et al., 2017). Dari hasil penelitian geokimia air asin di GLBK diperoleh kandungan unsur-unsur diantaranya $\mathrm{SiO} 2, \mathrm{Na}, \mathrm{K}, \mathrm{Mg}, \mathrm{Li}$, dan $\mathrm{B}$ yang diduga dipengaruhi oleh aktivitas panas bumi (Rizqiya, 2014; Rohmah, Lalasari, Wahyuadi, \& Natasha, 2018). Reservoir panas bumi ini diduga sebagai penyuplai letupan-letupan lumpur hangat yang juga membawa larutan kaya mineral termasuk belerang dan garam dengan konsentrasi tinggi konsentrasinya belerang 62.883 × $102 \mathrm{mg} / \mathrm{Kg}$, dan $\mathrm{NaCl} 57.15$ mg/L (Sa'diyah, Syarwani, \& Hadiantoro, 2017; Siregar \& Siregar, 2016). GLBK diduga memiliki temperatur yang lebih tinggi dibandingkan dengan temperatur yang keluar di permukaan. Dengan asumsi bahwa: (a) reaksi kimia pokok yang terjadi di dalam suatu reservoir dipengaruhi oleh temperatur pelarutan, (b) tersedianya unsur-unsur kimia yang diperlukan dalam reaksi di reservoir, (c) terjadinya kesetimbangan kimia antara air dan batuan dalam reservoir, (d) tidak ada evolusi atau percampuran dengan air yang berbeda selama tertranspot ke permukaan, dan (e) tidak terjadi kesetimbangan baru selama air tertransport dari reservoir ke permukaan (Fournier, 1981), maka kandungan unsur-unsur kimia di permukaan dapat digunakan sebagai indikator geotermometer reservoir (Ellis, 1979). Geotermometer ini merupakan suatu bentuk persamaan yang digunakan untuk memperkirakan temperatur di bawah permukaan (reservoir) sumber panas di GLBK berdasarkan konsep ketergantungan kesetimbangan kimia baik larutan maupun gas terhadap temperatur (W. Giggenbach, 1997; W. F. Giggenbach, 1988; Karingithi, 2009).

Tabel 1. Kandungan unsur kimia air asin Bledug Kuwu (Rizqiya, 2014) dan

(Sulistiyono, Lalasari, Mayangsari, \& Prasetyo, 2018).

\begin{tabular}{rr}
\hline Unsur & \multicolumn{1}{c}{ Kadar unsur $(\mathbf{p p m})$} \\
$\mathrm{Ca}$ & $341^{(\mathrm{a})}, 192.9^{(\mathrm{b})}, 3855.72^{(\mathrm{c})}$ \\
$\mathrm{Mg}$ & $39^{(\mathrm{a})}, 690.62^{(\mathrm{b})}, 1355.68^{(\mathrm{c})}$ \\
$\mathrm{Na}$ & $8016^{(\mathrm{a})}, 43479.8^{(\mathrm{b})}, 67543.3^{(\mathrm{c})}$ \\
$\mathrm{K}$ & $285^{(\mathrm{a})}, 133.21^{(\mathrm{b})}, 3065.69^{(\mathrm{c})}$ \\
$\mathrm{Li}$ & $9.81^{(\mathrm{a})}, 138.64^{(\mathrm{b})}, 310.11^{(\mathrm{c})}$ \\
$\mathrm{NH}_{3}$ & $16.67^{(\mathrm{a})}$ \\
$\mathrm{Cl}^{(\mathrm{a})}$ & $12702.99^{(\mathrm{a})}$ \\
$\mathrm{SO}_{4}$ & $27.29^{(\mathrm{a})}$ \\
$\mathrm{HCO}_{3}$ & $254.42^{(\mathrm{a})}$ \\
$\mathrm{H}_{2} \mathrm{~S}$ & $4.53^{(\mathrm{a})}$ \\
$\mathrm{B}$ & $44.98^{(\mathrm{a})}, 640.46^{(\mathrm{b})}, 1208.59^{(\mathrm{c})}$ \\
$\mathrm{Al}$ & $4.2^{(\mathrm{b})}, 41.06^{(\mathrm{c})}$ \\
\hline
\end{tabular}

(a)(Rizqiya, 2014)

(b) Brine water (Sulistiyono et al., 2018)

(c) Brine water (Sulistiyono et al., 2018) 


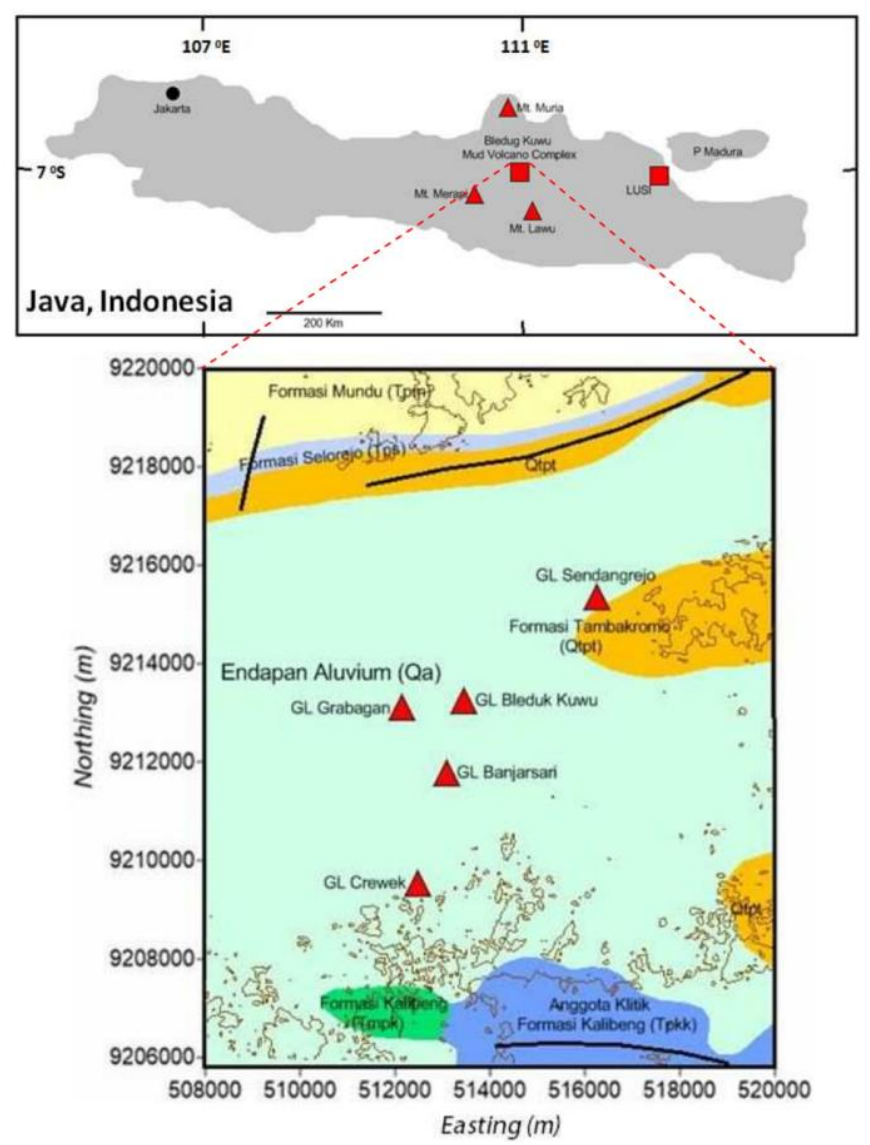

Gambar 1. Peta Geologi Komplek Gunung Lumpur Bledug Kuwu (Datun, Sukandarrumidi, \& Hermanto, 1996).

\section{METODE PENELITIAN}

Data yang dipakai dalam penelitian ini merupakan data sekunder kandungan unsur $\mathrm{Na}, \mathrm{K}, \mathrm{Mg}$, dan $\mathrm{Ca}$ dari air asin Bledug Kuwu yang telah dilakukan oleh (Rizqiya, 2014) yang ditunjukkan dalam tabel (1). Dari pengukuran kimia yang telah dilakukan oleh (Rizqiya, 2014), geotermometer yang memungkinkan digunakan adalah geotermometer $\mathrm{Na}-\mathrm{K}, \mathrm{Na}-\mathrm{K}-\mathrm{Ca}, \mathrm{Na}-\mathrm{K}-\mathrm{Ca}-\mathrm{Mg}$, yang melibatkan dua sampai lima unsur kimia yang terdapat pada sampel unsur kimia di GLBK mengacu pada (Sismanto \& Andayany, 2012) dan (Fournier, 1979). Persamaan geotermometer yang digunakan tersebut adalah sebagai berikut (indeks (s) adalah yang mengacu pada (Sismanto \& Andayany, 2012) dan Indeks (f) yang mengacu pada(Fournier, 1979):

Geotermometer (Na-K)s

Geotermometer ini merupakan geotermometer yang melibatkan unsur $\mathrm{Na}$ dan $\mathrm{K}$ yang ditulis sebagai,

$t\left({ }^{\circ} \mathrm{C}\right)=\frac{855.6}{\log \frac{[\mathrm{Na}]}{[\mathrm{K}]}+0.8573}-273.15$

dengan adalah konsentrasi Natrium dalam ppm, konsentrasi Kalium (ppm), dan temperatur terhitung (0C).

Geotermometer (Na-K)f

Geotermometer lainnya yang melibatkan unsur $\mathrm{Na}$ dan $\mathrm{K}$ dikembangkan oleh (Fournier, 1979) yang dinyatakan sebagai,

Estimasi temperatur bawah permukaan reservoir Gunung Lumpur Bledug Kuwu (GLBK)... Adhi, Wahyudi, Suryanto, Supriyanto, Ellianawati, Sismanto 
$T^{\circ} \mathrm{C}=\frac{1217}{\log \left(\frac{\mathrm{Na}}{K}\right)+1,438}-273,15$

Geotermometer (Na-K-Ca)s

Geotermometer ini merupakan geotermometer yang melibatkan unsur $\mathrm{Na}, \mathrm{K}$, dan $\mathrm{Ca}$, ditulis dalam bentuk

$t\left({ }^{\circ} \mathrm{C}\right)=\frac{1647}{\log \left(\frac{\mathrm{WNa}]}{[\mathrm{KI}]}+\beta \log \left(\frac{[\mathrm{Ca}]^{1 / 2}}{[\mathrm{Nad}]}\right)+2.24\right)}-$

273.15

dengan adalah konsentrasi Kalsium dalam ppm, $\beta=4 / 3$ untuk $\left([\mathrm{Ca}]^{1 / 2} /[\mathrm{Na}]\right)>1$ $\operatorname{dan} \beta=1 / 3$ untuk $\left([\mathrm{Ca}]^{1 / 2} /[\mathrm{Na}]\right)<1$ atau jika $t_{\beta=4 / 3}<100{ }^{0} \mathrm{C}$.

Geotermometer (Na-K-Ca-Mg)s

Geotermometer ini merupakan geotermometer yang melibatkan unsur $\mathrm{Na}, \mathrm{K}$, $\mathrm{Ca}$, dan $\mathrm{Mg}$, ditulis dalam bentuk

$t\left({ }^{0} \mathrm{C}\right)=2752.631 \times\left(\frac{[K]}{[\mathrm{Na}]}\right)^{0.26119} \times$

$\left(\frac{[\mathrm{Ca}]}{[\mathrm{Na}]^{2}}\right)^{0.06199} \times\left(\frac{[\mathrm{Mg}]}{[\mathrm{Na}]^{2}}\right)^{0.02798}-273.15$

dengan konsentrasi Magnesium.

\section{HASIL DAN PEMBAHASAN}

Perhitungan telah dilakukan menggunakan persamaan (1.1), (1.2), (1.3) dan (1.4) untuk mendapatkan hasil perkiraan temperatur dari reservoir sumber panas bawah permukaan Bledug Kuwu (GLBK). Persamaan yang dipakai tersebut memiliki tujuan yang sama yaitu untuk mendapatkan informasi dugaan temperatur reservoir bawah permukaan Gunung Lumpur Bledug Kuwu (GLBK), akan tetapi dengan pendekatan rumus yang berbeda. Temperatur reservoir panas bumi di bawah permukaan adalah menggunakan metode geotermometri, dengan cara mengukur secara tidak langsung temperatur berdasarkan zat kimia yang terlarut atau sebagai geotermometer larutan. (Gupta dan Roy, 2007). Geotermometer larutan digunakan untuk mengetahui kondisi hidrotermal di dalam reservoar panasbumi, yang meliputi kesetimbangan temperatur air panas dan batuan/mineral, serta digunakan untuk memprediksi termperatur reservoar panasbumi (Sismanto \& Andayany, 2012). Geotermometer larutan tersebut meliputi geotermometer: Na-K, Na-K-Ca, Na-K-Ca-Mg, silika, dan isotop (Fournier, 1979; Sismanto \& Andayany, 2012).

Kandungan unsur terlarut dalam larutan air GLBK dan rasio konsentrasinya dapat digunakan sebagai geothermometer untuk memperkirakan suhu reservoir. Zat terlarut tersebut merupakan unsur kationik meliputi unsur $\mathrm{Na}, \mathrm{K}, \mathrm{Ca}$ dan $\mathrm{Mg}$ (tabel 1), yang merupakan unsur kationik, dari data (Rizqiya, 2014), sedangkan Silika/Quarz tidak dilakukan perhitungan karena tidak tersedianya data. Dari hasil perhitungan menggunakan persamaan (1.1), (1.2), (1.3) dan (1.4) diperoleh hasil dugaan temperatur reservoir bawah permukaan GLBK berturut-turut sebesar $97.987^{\circ} \mathrm{C}, 148.354^{\circ} \mathrm{C}, 130.998^{\circ} \mathrm{C}$ dan $90.411^{\circ} \mathrm{C}$. Hasil estimasi temperatur sumber bawah permukaan (reservoir) ini memiliki perbedaan antara pendekatan menggunakan persamaan (1.1), (1.2), (1.3) dan (1.4) karena ada perbedaan pendekatan bentuk model dasar reaksi kimia mineral dalam reservoir sumber di bawah permukaan sehingga terjadi perbedaan pendekatan rumus yang dipakai. 
Hasil perhitungan menggunakan persamaan (1.1) sampai (1.4) di atas menghasilkan perkiraan temperatur reservoir sumber bawah permukaan di GLBK yang cukup tinggi berkisar antara $90.411^{\circ} \mathrm{C}$ sampai $148.534^{\circ} \mathrm{C}$. Dari hasil ini mengimplikasikan adanya dugaan kemungkinan terjadinya kontak antara reservoir air asin Gunung Lumpur Bledug Kuwu dengan suatu sumber panas vulkanik. Hasil perhitungan menggunakan geothermometer Na-K yang dirumuskan oleh (Fournier, 1979) dalam persamaan (1.2) , menghasilkan hasil yang lebih tinggi dibandingkan rumusan pada persamaan lainnya (persamaan (1.1), (1.3) dan (1.4) dengan hasil perhitungan sekitar $148.534{ }^{\circ} \mathrm{C}$, sedangkan persamaan geothermometer $\mathrm{Na}, \mathrm{K}, \mathrm{Ca}$ dan Mg (Persamaan (1.4) menghasilkan hasil perhitungan dengan nilai yang lebih rendah daripada yang lainnya yaitu sebesar kurang lebih $90.411{ }^{\circ} \mathrm{C}$. Perhitungan ini memberikan hasil yang berbeda akan tetapi masih berdekatan, karena masingmasing menggunakan pendekatan dan aproksimasi rumus yang berbeda.

Perhitungan yang telah dilakukan ini melengkapi hasil yang didapatkan (Rizqiya, 2014) melalui analisis struktur fraksi Kristal Natrium Klorida dari air asin yang keluar dari Gunung Lumpur Bledug Kuwu (GLBW) berdasarkan pola X-Ray Diffraction. Rizqiya (2014) juga meneliti kandungan unsur-unsur terlarut lainnya meliputi $\mathrm{Ca}, \mathrm{Mg}, \mathrm{Na}, \mathrm{K}, \mathrm{Li}, \mathrm{NH}_{3}, \mathrm{Cl}, \mathrm{SO}_{4}, \mathrm{HCO}_{3}, \mathrm{H}_{2} \mathrm{~S}$ dan Boron. Hasil yang didapatkan Siregar dan Siregar (2016) melalui analisis temperatur, unsur Belerang (S) dan salinitas GLBW. Dari hasil pengukuran temperatur di atas permukaan di GLBK menggunakan termometer oleh (Siregar \& Siregar, 2016) diperoleh bahwa temperatur rata-rata air asin yang keluar di atas permukaan GLBK adalah $32^{\circ} \mathrm{C}$ yang lebih tinggi dari temperatur lingkungan, dengan $\mathrm{PH}$ rata-rata lumpur 7.5 dan kandungan Belerang (S) cukup tinggi yaitu $62.883 \times 10^{2} \mathrm{mg} / \mathrm{Kg}$. Keberadaan $\mathrm{Li}$ sesuai hasil penelitian (Rizqiya, 2014) didukung hasil yang didapatkan (Sulistiyono et al., 2018) melalui ekstraksi Lithium (Li) dari air asin yang keluar dari GLBK. Dalam penelitiannya (Sulistiyono et al., 2018) menyelidiki pengaruh pelarut kimia pada endapan ion $\mathrm{Li}, \mathrm{Na}, \mathrm{K}, \mathrm{Ca}, \mathrm{Mg}, \mathrm{Al}$ dan $\mathrm{B}$ air asin GLBK dengan pelarut kimia yang Asam Oksalat yang diikuti dengan presipitasi kimia menggunakan Natrium Karbonat. Rangkuman unsur-unsur kimia yang terdapat dalam air asin GLBK ditunjukkan oleh tabel (1), yang semuanya menguatkan dugaan akan adanya kontak antara reservoir bawah permukaan GLBK dengan sumber panas Vulkanik, sehingga resevoir GLBK memiliki temperatur tinggi dalam bentuk sistem panasbumi GLBK, dengan estimasi temperatur reservoir sumber panas di bawah permukaan berkisar antara 90.411 sampai $148.534^{\circ} \mathrm{C}$.

\section{KESIMPULAN}

Dari hasil penelitian geokimia air asin GLBK yang mengandung gas $\mathrm{CO} 2$, unsur kimia $\mathrm{Na}, \mathrm{K}, \mathrm{Ca}, \mathrm{Mg}, \mathrm{Li}, \mathrm{NH} 3, \mathrm{Cl}, \mathrm{SO} 4, \mathrm{H} 2 \mathrm{~S}, \mathrm{~B}, \mathrm{Al}$ dan SiO2, mekanisme panasbumi diduga merupakan salah satu proses yang dominan sebagai pengontrol dan sumber dari Gas dan unsur kimia yang keluar dari GLBK. Dari hasil perhitungan menggunakan pendekatan metode geotermometri, temperatur reservoir sumber di bawah permukaan panasbumi GLBK diduga berkisar antara $90.411-148.354$ 0C.

\section{DAFTAR PUSTAKA}

Datun, M., Sukandarrumidi, S., \& Hermanto, B. S., N (Cartographer). (1996). Peta Geologi Lembar Ngawi (Edisi Kedua)

Ellis, A. (1979). Chemical geothermometry in geothermal systems. Chemical geology, 25(3), 219-226. 
Fournier, R. O. (1979). A revised equation for the $\mathrm{Na} / \mathrm{K}$ geothermometer. Transactions of the Geothermal Resources Council, 3, 221-224.

Fournier, R. O. (1981). Application of water geochemistry to geothermal exploration and reservoir engineering. Geothermal System: Principles and Case Histories, 109-143.

Giggenbach, W. (1997). The origin and evolution of fluids in magmatichydrothermal systems. Geochemistry of hydrothermal ore deposits.

Giggenbach, W. F. (1988). Geothermal solute equilibria. derivation of Na-K-Mg-Ca geoindicators. Geochimica et cosmochimica acta, 52(12), 2749-2765.

Istadi, B. P., Wibowo, H. T., Sunardi, E., Hadi, S., \& Sawolo, N. (2012). Mud volcano and its evolution. In Earth sciences (pp. 376-434): IntechOpen.

Karingithi, C. W. (2009). CHEMICAL GEOTHERMOMETERS FOR GEOTHERMAL EXPLORATION Paper presented at the Presented at Short Course IV on Exploration for Geothermal Resources, at Lake Naivasha, Kenya.

Queißer, M., Burton, M., Arzilli, F., Chiarugi, A., Marliyani, G. I., Anggara, F., \& Harijoko, A. (2017). CO2 flux from Javanese mud volcanism. Journal of Geophysical Research: Solid Earth, 122(6), 4191-4207.

Rizqiya, F. (2014). Analisis Struktur Fraksi Fasa Kristal Natrium Klorida dari Brine Water Bledug Kuwu Sebagai Fungsi Waktu Kristalisasi Berdasarkan Pola Difraksi Sinar $X$ (X Ray Diffraction). (Sarjana). Universitas Islam Negeri Sunan Kalijaga, Yogyakarta.

Rohmah, M., Lalasari, L. H., Wahyuadi, J., \& Natasha, N. C. (2018). Lithium recovery from Bledug Kuwu Mud volcano using water leaching method. Paper presented at the 2018 IEEE International Conference on Innovative Research and Development (ICIRD).

Sa'diyah, K., Syarwani, M., \& Hadiantoro, S. (2017). Adsorption of Nickel in Nickel Sulphate Solution (NiSO4) by Lapindo Mud. Jurnal Bahan Alam Terbarukan, 6(1), 39-44. doi:https://doi.org/10.15294/jbat.v6i1.7963

Siregar, S., \& Siregar, N. I. (2016). Analisis dan Pemanfaatan Unsur Belerang dan Salinitas Lumpur Bledug Kuwu di Desa Kuwu, Kecamatan Kradenan, Kabupaten Grobongan, Jawa Tengah. POSITRON: Berkala IImiah Fisika, 6(1), 40-42.

Sismanto, S., \& Andayany, H. (2012). Pengembangan Persamaan Geotermometer Empiris Untuk Estimasi Suhu Reservoir Sumber Mata Air Panas Paper presented at the Prosiding Pertemuan IImiah XXVI HFI Jateng \& DIY, Purworejo.

Sulistiyono, E., Lalasari, L. H., Mayangsari, W., \& Prasetyo, A. (2018). Study of lithium extraction from brine water, Bledug Kuwu, Indonesia by the precipitation series of oxalic acid and carbonate sodium. Paper presented at the AIP Conference Proceedings.

Syaichurrozi, I. (2017). Study of the Potential Anaerobic Co-digestion for Biogas Production from Salvinia molesta and Rice Straw. Jurnal Bahan Alam Terbarukan, 6(1), 61-67. 